\title{
THE DEVELOPMENT OF THE SPORTS CAREERS OF THE BEST DECATHLETES IN THE WORLD AND IN POLAND IN THE YEARS 1985-2015
}

\author{
BARTOSZ DZIADEK ${ }^{1}$, JANUSZ ISKRA ${ }^{2}$, KRZYSZTOF PRZEDNOWEK ${ }^{1}$ \\ ${ }^{1}$ University of Rzeszów, Faculty of Physical Education, Department of Methodology and Computer Science \\ ${ }^{2}$ Opole University of Technology, Faculty of Physical Education and Physiotherapy, Chair of Individual Sports
}

Mailing address: Bartosz Dziadek, University of Rzeszów, Department of Methodology and Computer Science, 3 Towarnickiego Street, 35-959 Rzeszów, tel.: +48 17 8721872, fax: +48 17 8721861, e-mail: bdziadek@ur.edu.pl

\begin{abstract}
Introduction. The main goal of the study was to examine the changes in the scores achieved by a group of the best decathletes in Poland and in the world over the duration of their entire sports careers. Material and methods. The study examined the careers of 25 top decathletes in Poland and 25 top decathletes in the world who achieved their best scores in the decathlon in the years 1985-2015. Changes in their performance were analysed using three research protocols, which explored the relationships between the decathletes' performance and their age, the number of years of training completed, and the number of years elapsed before and after the decathletes achieved their personal best scores. In order to analyse the data, some basic descriptive statistics, performed segmented regression, and computed fixed-base and chain indices were calculated. Conclusions. The findings of the current study indicate that decathletes achieve the best outcomes between the ages of 25 and 30 . Furthermore, it was found that the time when the personal best scores were attained was preceded by the greatest increases in the level of performance and followed by the largest decreases in performance. Determining the way performance outcomes change in particular years of the career of a decathlete can help manage their training in different phases of their career more effectively.
\end{abstract}

Key words: decathlon, development of sports career, analysing changes in performance outcomes

\section{Introduction}

The decathlon is one of the most difficult and most complex disciplines in track and field athletics. Since 1911, the men's decathlon has consisted of 4 running events, 3 jumping events, and 3 throwing events [1]. The events take place over two days. On day 1 , the 100-m race, long jump, shot put, high jump, and 400-m race are held, whereas on day 2 , the 110 -m hurdle race, discus throw, pole vault, javelin throw, and 1500-m race are organised. The best outcomes achieved in each event are calculated into points, according to the scoring tables for the decathlon, which are then added up. The total number of points achieved in the events held on both days of the decathlon determines the decathlete's rank in the competition. The scoring tables which are currently used were designed in 1985.

From a physiological point of view, the decathlon involves the aerobic (1500-m race), glycolytic (400-m race), and phosphagen (100-m race, jumping, and throwing) systems [2]. Motor performance in the decathlon depends mainly on the athlete's speed-strength capacities [3]. As for the complexity of the movement performed in the decathlon, both events which involve simple movement (the 100-m, 400-m, and 1500-m races) and those which involve complex movement (the pole vault and 110 -m hurdle race) are held [4, 5].

Changes in the outcomes of performance in athletics have been analysed by several authors, both from Poland and all over the world. Maszczyk [6] carried out an analysis of the variability of the outcomes achieved by world athletes in selected athletics events in the years 1946-2011. The models he developed additionally made it possible to predict outcomes for the years to come. Changes in performance have also been investigated in groups of Olympic finalists [7]. These analyses have shown how outcomes in particular types of throwing events improved over several dozen years.

Other publications regarding this issue have, among others, reported on the way the careers of the best athletes in the world in selected disciplines developed [8] and analysed changes in performance outcomes over shorter (2003-2013) [9] and longer (1946-2013) [10] periods of time. In the case of the decathlon, analysing the mark (total number of points) obtained by the athletes is only a starting point for more detailed analyses focusing on the outcomes achieved in each event.

Analyses such as the ones mentioned above allow researchers to monitor the evolution of performance outcomes in each discipline, and thus the evolution of the discipline itself, as well as making it possible to track the rate at which the outcomes of Polish and world athletes are improving. That is why in this study selected methods of analysing changes in data were used to examine the evolution of the outcomes in the decathlon, taking into account various phases of the sports career of decathletes [11].

The main goal of the study presented in this article was to investigate the changes in the outcomes achieved by the best decathletes in Poland and in the world over the duration of their entire sports careers, using selected statistical methods. 


\section{Material and methods}

The careers of the top 25 athletes in Poland and the top 25 athletes in the world who achieved their personal best scores in the decathlon in the years 1985-2015 were analysed. The study covers the period beginning in 1985 because this is the year when the scoring tables for the decathlon were last revised. The data of the best 10 decathletes from Poland and the world were obtained from the International Association of Athletics Federations (IAAF) [12] and the Polish Athletics Association [13]. The remaining data were collected from publications by statisticians, for example the annual published by the Association of Track and Field Statisticians (ATFS) authored by Matthews (1985-2013) [14], the annuals by van Kuijen [15], as well as the data gathered by H. Gąszczak for the Polish Athletics Association [13] and the data available from the website [16] run by J. Salamistu. The missing data were obtained from journals on statistics in athletics and journals on athletics ("Legkaja Atletyka", "Atletika", "Lekkoatleta", and many others).

The data (449 records) made it possible to analyse the evolution of the outcomes of Polish and world athletes, which was done using the following three protocols:

- Protocol 1 - an analysis of the scores with regard to the age of the decathletes;

- Protocol 2 - an analysis of the scores with regard to the years of training completed;

- Protocol 3 - an analysis of the scores with regard to the number of years elapsed before and after the decathletes achieved their record scores.

Only the data which included at least 7 cases were analysed in the protocols $(n \geq 7)$. The process of creating particular records is described in detail in the work by Plewnia [17].

The analysis was conducted using fixed-base and chain indices [6]. A segmented model was used to analyse the changes in the mean scores in the protocols [18]. This type of regression analysis is characterised by the fact that the explanatory variable is divided into segments, and a separate linear model is determined for each segment. The coefficient of determination $\left(R^{2}\right)$, which made it possible to measure the goodness-of-fit of the model to the data, was additionally calculated.

The changes in the outcomes achieved by the decathletes were first assessed using fixed-base indices $i_{\frac{\tau}{\kappa}}$, the base period being the first outcome in the protocol, which were determined using the following equation:

$$
i_{\frac{\tau}{\kappa}}=\frac{y_{\tau}}{y_{\kappa}},
$$

where $y_{\tau}=$ the level of the phenomenon in the period under investigation and $y_{\kappa}=$ the level of the phenomenon in the base period.

The changes in the data were then examined using chain indices, in which the values in the period of investigation are related to those in the immediately preceding period. The following equation was used to calculate chain indices:

$$
i_{\frac{\tau}{\tau-1}}=\frac{y_{\tau}}{y_{\tau-1}}
$$

where $y_{\tau}=$ the level of the phenomenon in the period under investigation and $y_{\tau-1}=$ the level of the phenomenon in the preceding period.

\section{Results}

The data used in all three protocols are presented in tables 1 (world athletes) and 2 (Polish athletes) using basic descriptive statistics.

\begin{tabular}{|c|c|c|c|c|c|c|c|c|}
\hline \multicolumn{9}{|c|}{ World } \\
\hline \multicolumn{3}{|c|}{ Protocol 1} & \multicolumn{3}{|c|}{ Protocol 2} & \multicolumn{3}{|c|}{ Protocol 3} \\
\hline Age & $n$ & $\bar{x} \pm s d$ & $\begin{array}{l}\text { Years } \\
\text { of } \\
\text { training }\end{array}$ & $n$ & $\bar{x} \pm s d$ & $\begin{array}{c}\text { Years } \\
\text { before } \\
\text { and after } \\
\text { record } \\
\text { score }\end{array}$ & $n$ & $\bar{x} \pm s d$ \\
\hline 16 & $1^{*}$ & $6873 \pm 0$ & 1 & 25 & $7250 \pm 688$ & -13 & $1^{*}$ & $6671 \pm 0$ \\
\hline 17 & $4^{*}$ & $6455 \pm 882$ & 2 & 25 & $7667 \pm 515$ & -12 & $1^{*}$ & $7351 \pm 0$ \\
\hline 18 & 10 & $7190 \pm 464$ & 3 & 23 & $7992 \pm 401$ & -11 & $1^{*}$ & $7771 \pm 0$ \\
\hline 19 & 18 & $7465 \pm 291$ & 4 & 22 & $8184 \pm 438$ & -10 & $3^{*}$ & $6570 \pm 1226$ \\
\hline 20 & 18 & $7614 \pm 512$ & 5 & 23 & $8298 \pm 329$ & -9 & 7 & $7154 \pm 725$ \\
\hline 21 & 18 & $7995 \pm 419$ & 6 & 25 & $8390 \pm 330$ & -8 & 10 & $7403 \pm 395$ \\
\hline 22 & 23 & $8266 \pm 279$ & 7 & 22 & $8533 \pm 197$ & -7 & 12 & $7662 \pm 478$ \\
\hline 23 & 24 & $8279 \pm 309$ & 8 & 16 & $8506 \pm 194$ & -6 & 17 & $7757 \pm 543$ \\
\hline 24 & 22 & $8445 \pm 267$ & 9 & 21 & $8512 \pm 226$ & -5 & 19 & $7961 \pm 465$ \\
\hline 25 & 22 & $8488 \pm 237$ & 10 & 15 & $8565 \pm 146$ & -4 & 20 & $8126 \pm 409$ \\
\hline 26 & 20 & $8502 \pm 204$ & 11 & 17 & $8482 \pm 340$ & -3 & 22 & $8273 \pm 397$ \\
\hline 27 & 21 & $8603 \pm 221$ & 12 & 16 & $8450 \pm 307$ & -2 & 23 & $8410 \pm 259$ \\
\hline 28 & 20 & $8553 \pm 252$ & 13 & 11 & $8197 \pm 542$ & -1 & 23 & $8455 \pm 222$ \\
\hline 29 & 13 & $8486 \pm 337$ & 14 & $6^{*}$ & $8406 \pm 351$ & 0 & 25 & $8735 \pm 135$ \\
\hline 30 & 14 & $8465 \pm 262$ & 15 & $5^{*}$ & $8292 \pm 191$ & 1 & 17 & $8550 \pm 190$ \\
\hline 31 & 12 & $8310 \pm 336$ & 16 & $4^{*}$ & $8264 \pm 203$ & 2 & 18 & $8442 \pm 262$ \\
\hline 32 & 11 & $8183 \pm 445$ & 17 & $4^{*}$ & $8219 \pm 394$ & 3 & 18 & $8353 \pm 376$ \\
\hline 33 & 7 & $8268 \pm 308$ & 18 & $2^{*}$ & $8119 \pm 173$ & 4 & 15 & $8395 \pm 283$ \\
\hline 34 & $4^{*}$ & $8164 \pm 143$ & 19 & $2^{*}$ & $8184 \pm 232$ & 5 & 9 & $8311 \pm 226$ \\
\hline 35 & $2^{*}$ & $8184 \pm 232$ & 20 & & & 6 & 11 & $8224 \pm 343$ \\
\hline 36 & & & 21 & $1^{*}$ & $8109 \pm 0$ & 7 & $6^{*}$ & $8262 \pm 309$ \\
\hline 37 & $1^{*}$ & $8109 \pm 0$ & 22 & $1^{*}$ & $8097 \pm 0$ & 8 & $3^{*}$ & $8145 \pm 113$ \\
\hline \multirow[t]{4}{*}{38} & $1^{*}$ & $8097 \pm 0$ & & & & 9 & $2^{*}$ & $8193 \pm 220$ \\
\hline & & & & & & 10 & $1^{*}$ & $7756 \pm 0$ \\
\hline & & & & & & 11 & $1^{*}$ & $8109 \pm 0$ \\
\hline & & & & & & 12 & $1^{*}$ & $8097 \pm 0$ \\
\hline
\end{tabular}

Table 1. Basic descriptive statistics for the group of world athletes

* - data not included in the analysis $(\mathrm{n}<7)$.

The models which represent the trends in the data (fig. 1) indicate that the outcomes achieved by both Polish and world decathletes analysed in all three protocols can be divided into two segments: an increasing one and a decreasing one. The trend line for the first segment, which has a positive slope, reflects the greatest improvement in the outcomes of the decathletes, and the one for the second segment, which has a negative slope, depicts a drop in the outcomes achieved by the decathletes after they attained their personal best score. There is one exception in this respect, however: in the Polish group in the second protocol both equations of the segmented model have a positive coefficient (fig. ld). This would mean that the performance of Polish decathletes whose outcomes were examined in the study progressed during most of their career. The results of the analysis indicate that the linear models used in the study fit the data well $\left(R^{2} \geq 0.89\right)$. The models which fit the best were those 
Table 2. Basic descriptive statistics for the group of Polish athletes

\begin{tabular}{|c|c|c|c|c|c|c|c|c|}
\hline \multicolumn{2}{|c|}{ Protocol 1} & \multicolumn{3}{c|}{ Poland } \\
\hline Wiek & $n$ & $\bar{x} \pm s d$ & $\begin{array}{c}\text { Years } \\
\text { of } \\
\text { training }\end{array}$ & $n$ & $\bar{x} \pm s d$ & $\begin{array}{c}\text { Years } \\
\text { before } \\
\text { and after } \\
\text { record } \\
\text { score }\end{array}$ & $n$ & $\bar{x} \pm s d$ \\
\hline 16 & $1^{*}$ & $5470 \pm 0$ & 1 & 18 & $6756 \pm 514$ & -10 & $2^{*}$ & $6582 \pm 621$ \\
\hline 17 & $3^{*}$ & $6426 \pm 273$ & 2 & 15 & $7057 \pm 301$ & -9 & $2^{*}$ & $6999 \pm 33$ \\
\hline 18 & 10 & $6833 \pm 325$ & 3 & 19 & $7210 \pm 209$ & -8 & $2^{*}$ & $7431 \pm 9$ \\
\hline 19 & 9 & $7072 \pm 296$ & 4 & 21 & $7367 \pm 241$ & -7 & $2^{*}$ & $7416 \pm 221$ \\
\hline 20 & 15 & $7194 \pm 235$ & 5 & 19 & $7427 \pm 262$ & -6 & $4^{*}$ & $6577 \pm 205$ \\
\hline 21 & 17 & $7232 \pm 296$ & 6 & 20 & $7479 \pm 281$ & -5 & 8 & $6847 \pm 621$ \\
\hline 22 & 16 & $7315 \pm 266$ & 7 & 17 & $7504 \pm 327$ & -4 & 14 & $7014 \pm 366$ \\
\hline 23 & 18 & $7318 \pm 347$ & 8 & 11 & $7413 \pm 455$ & -3 & 16 & $7232 \pm 411$ \\
\hline 24 & 18 & $7481 \pm 394$ & 9 & 7 & $7634 \pm 307$ & -2 & 17 & $7355 \pm 350$ \\
\hline 25 & 14 & $7596 \pm 305$ & 10 & $5^{*}$ & $7441 \pm 568$ & -1 & 19 & $7472 \pm 306$ \\
\hline 26 & 14 & $7596 \pm 283$ & 11 & $5^{*}$ & $7753 \pm 645$ & 0 & 25 & $7720 \pm 280$ \\
\hline 27 & 10 & $7573 \pm 454$ & 12 & $2^{*}$ & $7665 \pm 87$ & 1 & 21 & $7374 \pm 315$ \\
\hline 28 & 8 & $7385 \pm 343$ & 13 & $2^{*}$ & $7365 \pm 8$ & 2 & 16 & $7305 \pm 293$ \\
\hline 29 & $3^{*}$ & $7340 \pm 387$ & 14 & $2^{*}$ & $7171 \pm 217$ & 3 & 10 & $7290 \pm 211$ \\
\hline 30 & $2^{*}$ & $7732 \pm 528$ & 15 & & & 4 & $5^{*}$ & $7261 \pm 211$ \\
\hline 31 & $3^{*}$ & $7364 \pm 355$ & 16 & & & 5 & & \\
\hline 32 & $1^{*}$ & $7371 \pm 0$ & 17 & & & 6 & & \\
\hline 33 & $1^{*}$ & $7324 \pm 0$ & 18 & & & 7 & & \\
\hline & & & & & & & \\
\hline
\end{tabular}

* - data not included in the analysis $(\mathrm{n}<7)$.

created for world decathletes in the third protocol $\left(\mathrm{R}^{2}=0.98\right.$; $\mathrm{R}^{2}=0.98$ ), and the models which had the lowest goodness-offit were those for Polish decathletes in the same protocol $\left(\mathrm{R}^{2}=\right.$ $\left.0.93 ; R^{2}=0.89\right)$. The values of the coefficients of determination calculated for the data indicate that the method of modelling was selected well.

As shown in figure 1, the careers of top Polish decathletes were shorter than those of top decathletes in the world. Four phases can be identified in the careers of world athletes. The first one, which lasted 6 years, was characterised by a 15\% increase in the outcomes achieved. Then, the level of the decathletes' performance stabilised (at 8477 points) for approximately 3 years. After these two phases, the decathletes in the world group usually attained their personal best score, and afterwards their scores decreased. In contrast, the careers of Polish decathletes developed less dynamically, and distinct phases could not be clearly identified. In this group, outcomes improved continuously by $11 \%$ until the record score was attained. Polish decathletes performed the best at the ages of 25-26 years (obtaining 7596 points), and afterwards their performance deteriorated.

As far as the data concerning the number of years elapsed before and after achieving the record scores are concerned, figure le and if shows the period preceding their attainment, which was characterised by continuous improvement in performance, and the period after the best scores were achieved, during which performance deteriorated. Both of these periods were shorter in the Polish group. When the same periods before ( 5 years) and after ( 3 years) achieving the best personal outcome were examined for both groups, it was found that scores increased by $13 \%$ in the Polish group and $10 \%$ in the world group in the former period and decreased by $6 \%$ in the Polish group and $4.6 \%$ in the world group in the latter period.

The fixed-based indices, which were additionally calculated and analysed and where the first outcome in the respective protocol was used as the base period [6], are shown in figure 2a, $c$, and e. The values of the indices and the graphs which were generated confirm the observations regarding the progression of the sports careers of the decathletes in the two groups described above.

In the group of the best decathletes in the world, the first phase of the sports career is characterised by a dynamic increase compared to the base period. The indices for the period of stabilisation which follows, on the other hand, increase only slightly and remain on a similar level. As for the period when the personal best score was achieved, this is when the greatest increase in the values of the indices can be observed. In the final phase of their careers, top decathletes in the world achieved lower and lower outcomes. The values of the fixed-base indices are higher in this group than in the group of Polish decathletes. When it comes to the graph for the age of the decathletes (fig. 2a), the highest mean increase compared to the base period in the Polish group was $11.11 \%$, whereas that in the world group it was $19.65 \%$.

The changes in performance before and after achieving the personal best score are depicted in figure 2e. When the same periods before and after attaining the best scores were examined in both groups, it was found that the increases and decreases in the values of the fixed-base indices were on a similar level (the values increased by $11 \%$ and decreased by $6 \%$ ).

The chain indices [6], which are shown in figure $2 \mathrm{~b}, \mathrm{~d}$, and $\mathrm{f}$, also indicate that the scores of both groups increased until the best scores were achieved. Then the values of the indices become lower, which means that the scores decreased.

As far as the values of the indices and age of the decathletes are concerned (fig. 2b), they changed considerably in the first phase of the sports career in the world group; it is in this phase that the most significant increases and decreases in the index compared to the preceding period were observed. The greatest increases in this group were found for the ages of 21 (3\%) and 24 $(2 \%)$ years, and the greatest decreases were noted for the ages of $20(2 \%)$ and $22-23(5 \%)$ years. At the age of 27 , the decathletes achieved their record scores, and this year in their career was characterised by a $1 \%$ increase compared to the preceding year. In the group of Polish decathletes, the values of the indices changed in a less dynamic way. The greatest decreases were found for the ages of 20-21 years (3\%), 25-26 years, and 28 years $(2 \%)$. The most considerable increase was noted for the age of 24 years $(3 \%)$, which is when the decathletes attained their personal best scores.

As for the following years of the careers of the decathletes in both groups (fig. 2d), the chain indices do not vary much. A continuous decrease in the outcomes achieved by the best decathletes in the world can be observed starting from the $10^{\text {th }}$ year of training, where the chain indices are equal to $i \frac{\tau}{\tau-1}<1$. Minor decreases in the values of the indices were found for the $8^{\text {th }}(2 \%), 11^{\text {th }}(1.6 \%)$, and $13^{\text {th }}(2.5 \%)$ years of training, and minor increases were found for the $7^{\text {th }}, 9^{\text {th }}, 10^{\text {th }}$, and $12^{\text {th }}$ years $(1 \%)$. In the group of Polish athletes, the greatest decreases were observed for the $3^{\text {rd }}(2.3 \%), 5^{\text {th }}(1.3 \%)$, and $8^{\text {th }}(1.6 \%)$ years of training. The most considerable increase was found for the $9^{\text {th }}$ year of training, and it amounted to $4.2 \%$.

The results obtained in the third protocol (fig. 2f) show that the outcomes achieved by both groups changed in a dynamic 
a)

$y_{1}=216 x+3358\left(R^{2}=0.96\right) ; y_{2}=-41.79 x+9641\left(R^{2}=0.95\right)$

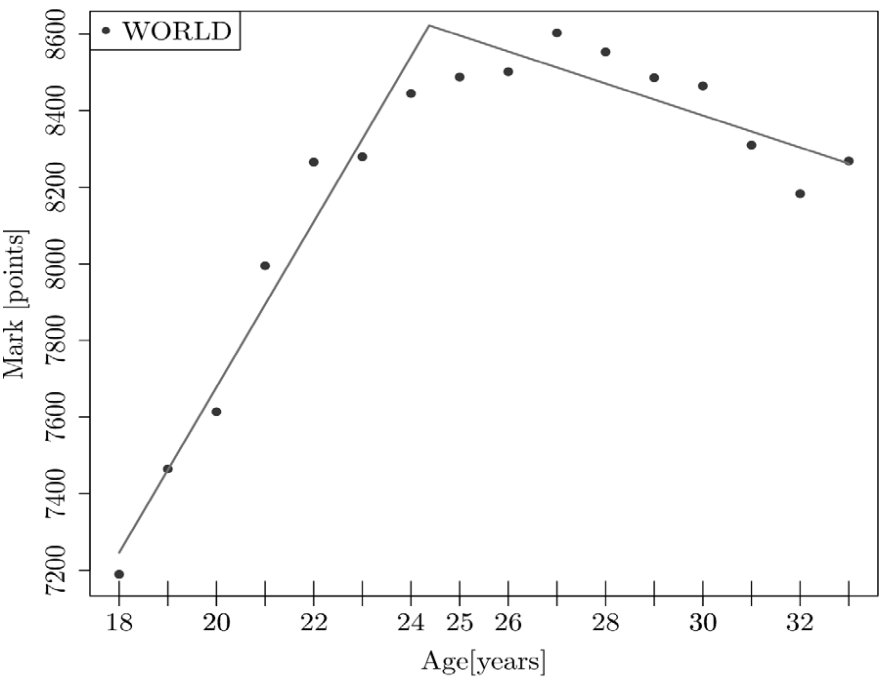

c)

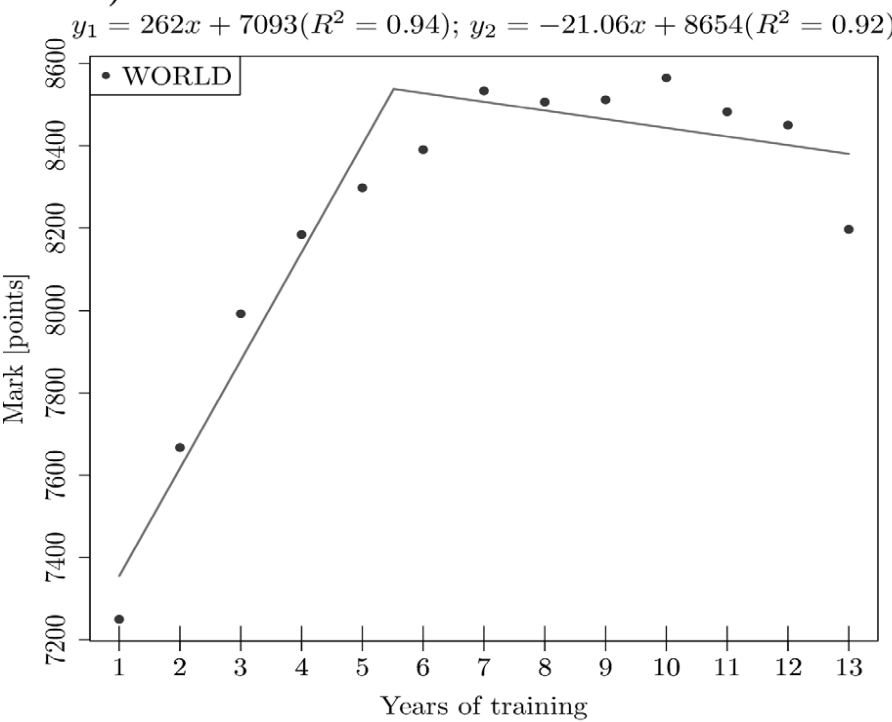

e)

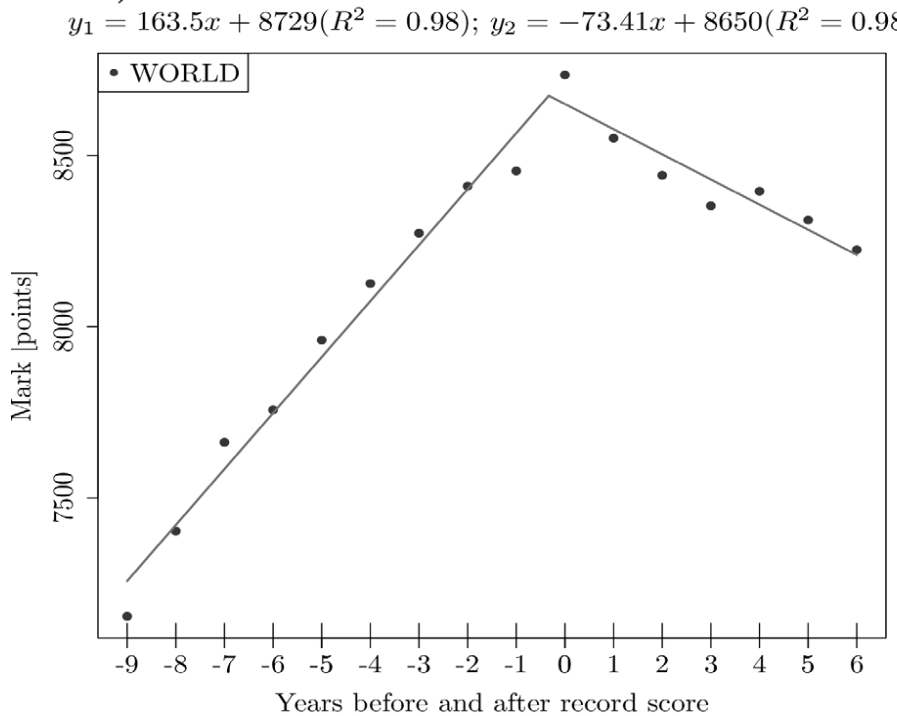

b)

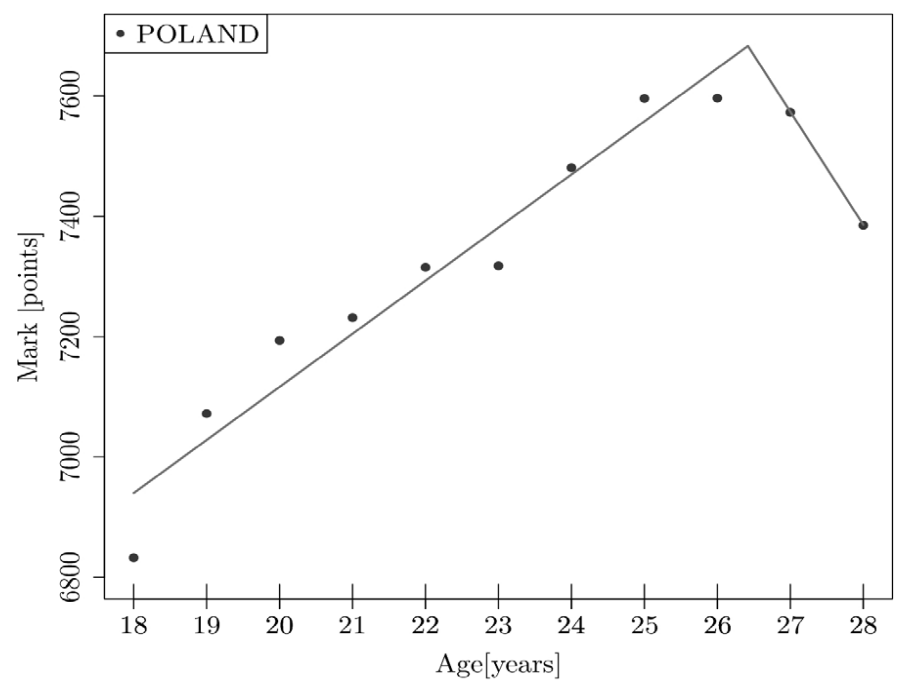

d)

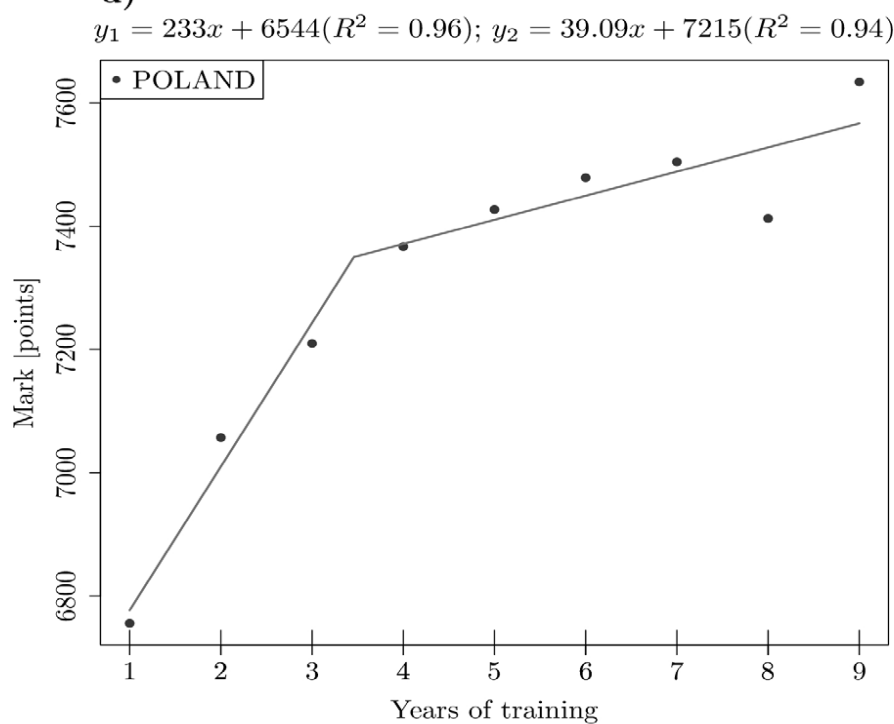

f)

$y_{1}=159.2 x+7661\left(R^{2}=0.93\right) ; y_{2}=-135.9 x+7626\left(R^{2}=0.89\right)$

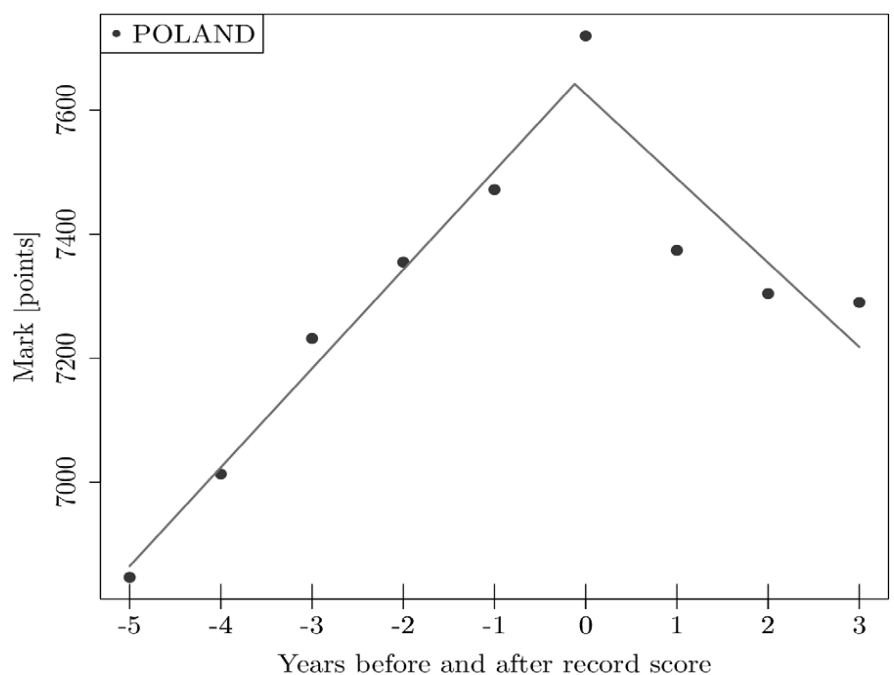

Figure 1. Trend lines obtained for protocols 1 (a-b), 2 (c-d), and 3 (e-f) 
a)

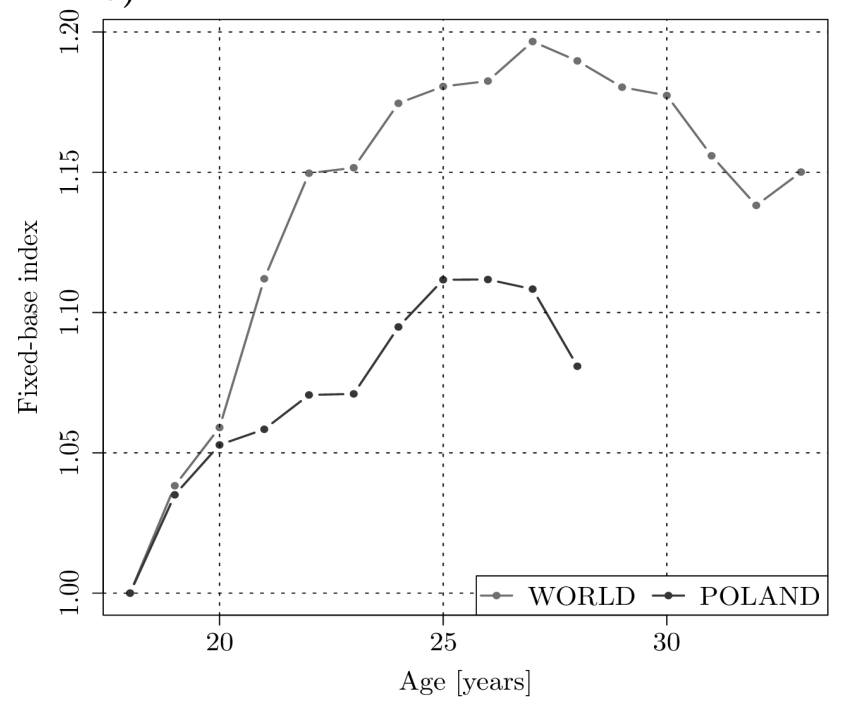

c)

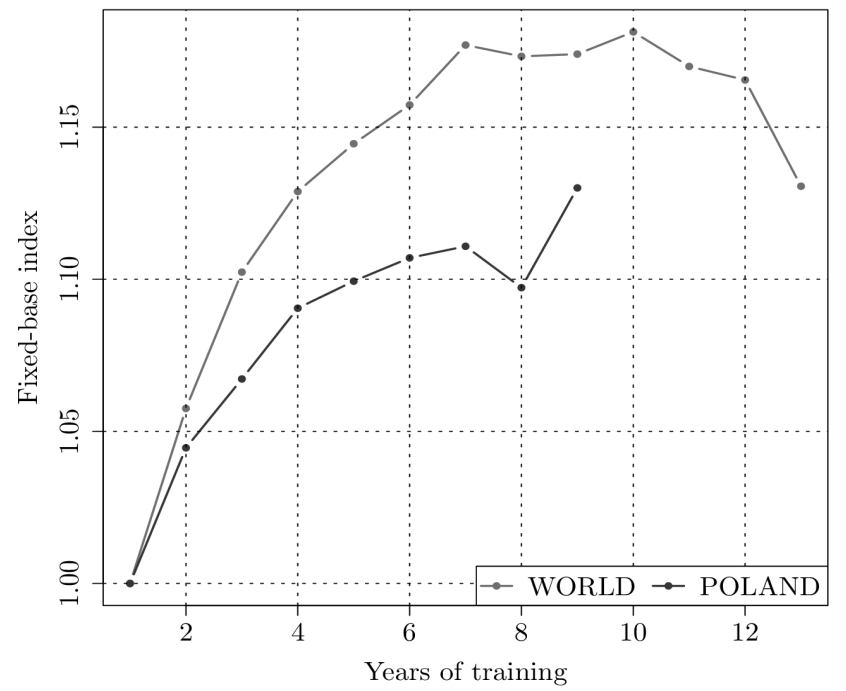

e)

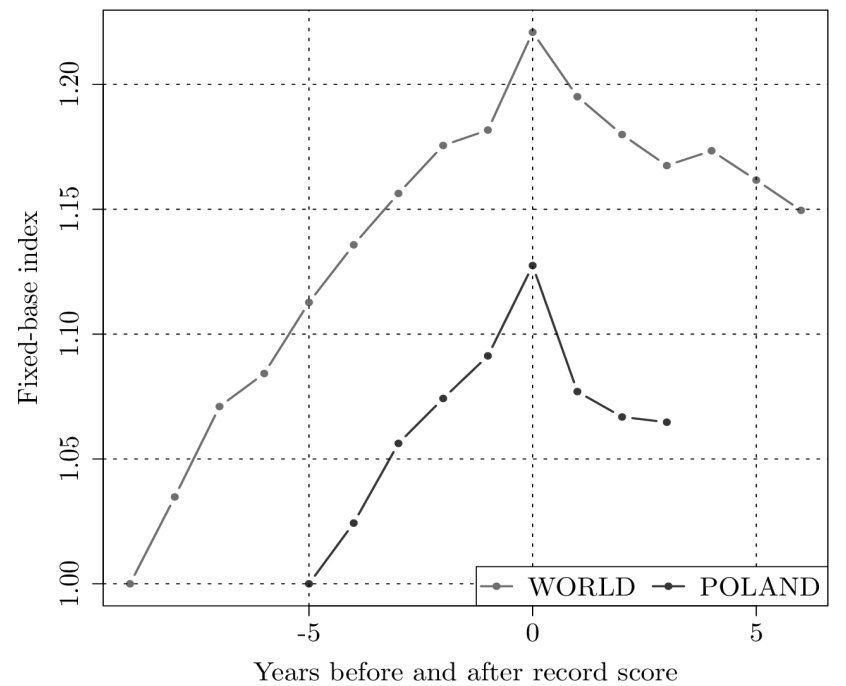

b)
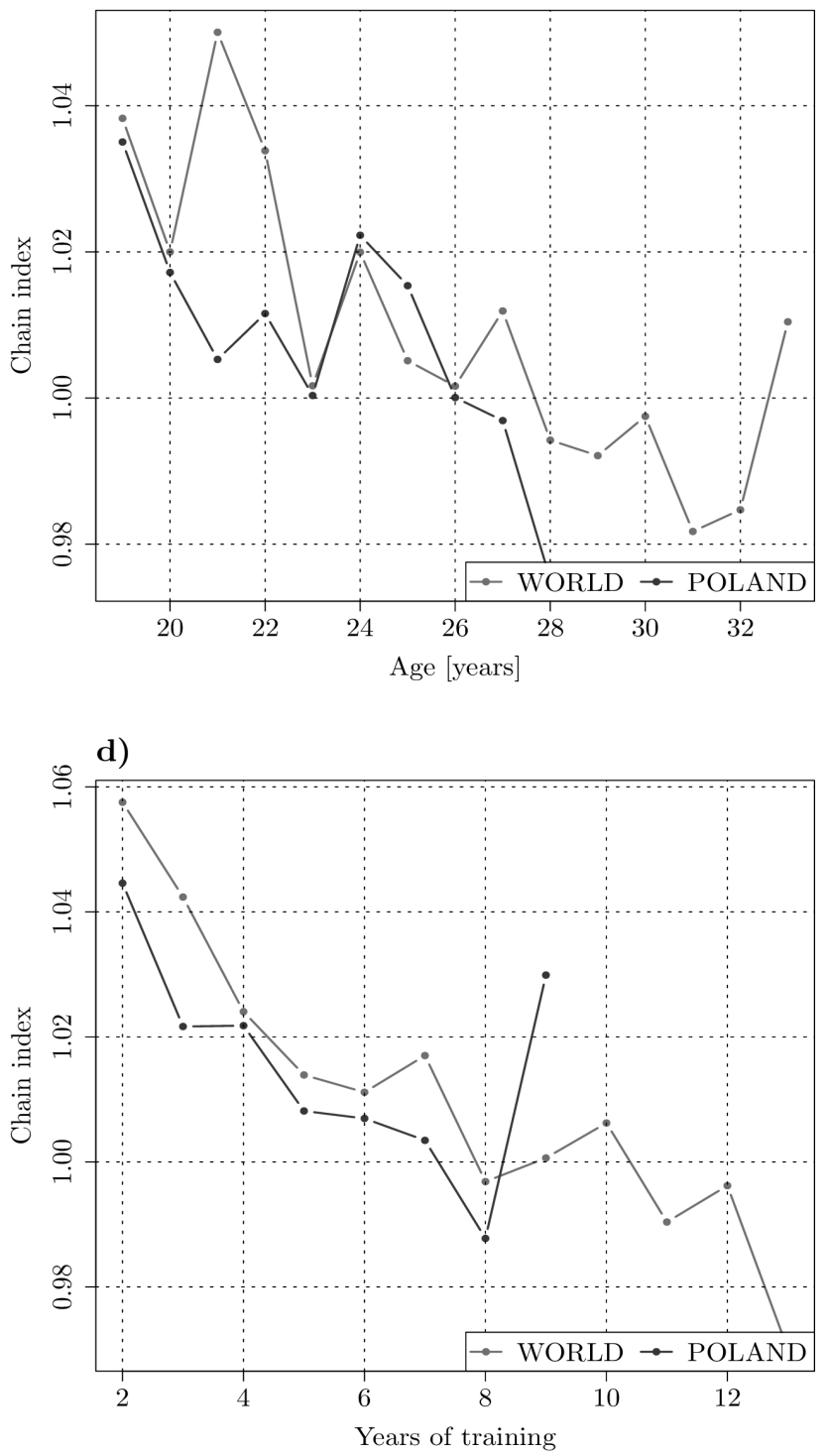

f)

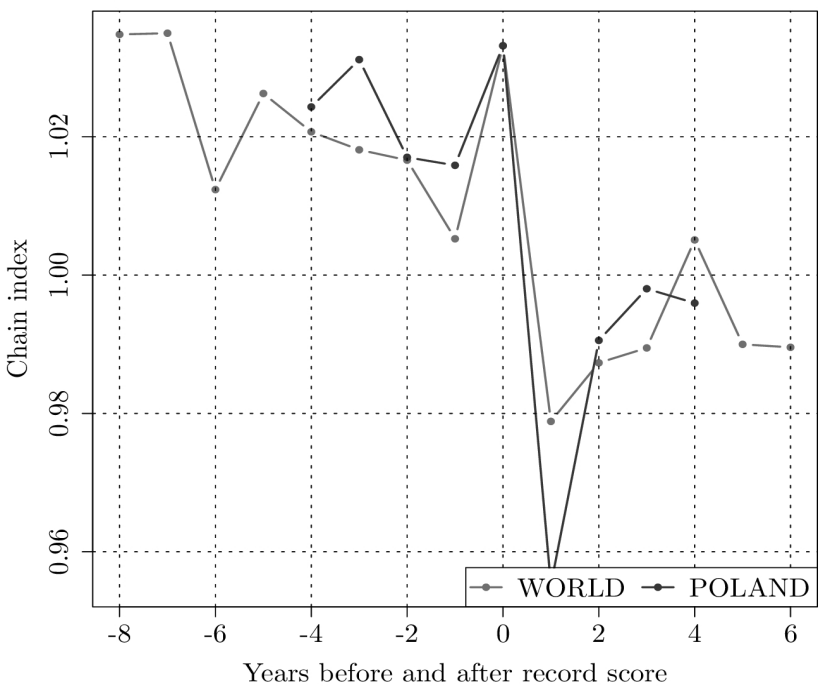

Figure 2. Fixed-base indices (a, c, and e) and chain indices (b, d, and f) obtained for the three protocols 
way. After the decathletes achieved their personal best score, their outcomes deteriorated, and the values of the chain indices become lower (by $7.8 \%$ in the Polish group and $5.4 \%$ for the world group).

\section{Discussion}

The age at which athletes attain the best outcomes has been examined by several authors, including Polish authors such as Ważny and Sozański [19, 20, 21, 22]. Analyses aimed at establishing the optimal age for achieving superior outcomes in sports in all of the disciplines in athletics were conducted already before the Second World War: pioneering research which monitored the age at which elite German athletes achieved their best outcomes was carried out in 1933 [23].

However, determining the role of age in the process of sports training requires analysing not only the age when athletes achieve their personal best scores, but also the age at which they were selected for competitive sports, the duration of the general and specific training periods, and the duration of their sports careers. One Polish scholar who analysed entire sports careers using mathematical methods was Ważny [24], whose work was published in 1981. Since then sport has changed and so have the methods used in statistical analyses.

In the past few years, the decathlon has undergone significant transformation, as athletes no longer perform in a similar and rather "average" way in all of the events: they now display superior performance in several similar events. For example, the current holder of the world record, Ashton Eaton, has worldclass achievements in short-distance races (the 100-m and 400$\mathrm{m}$ races and the $110-\mathrm{m}$ hurdle race) and the long jump, but he also performs very well in the 400-m hurdle race, which is not part of the decathlon [12].

The age at which decathletes become champions differs significantly. The youngest Olympic champion in the history of this complex discipline was Bob Mathias, an American, who was 17 years and 263 days old when he won his first gold medal in 1948. On the other hand, the oldest world champion was 32 years and 279 days old; this was Roman Šeberle, an athlete from the Czech Republic [25, 26].

Apart from examining the periods when athletes achieve their record scores, it is also important to analyse the periods of rising performance which lead to the best scores and those during which performance remains on the highest level [22].

The analysis shows that it takes top world athletes approximately 10 years of training to achieve their best personal scores, and superior performance is maintained for 6 years, whereas the span of the careers of Polish decathletes is shorter, and in

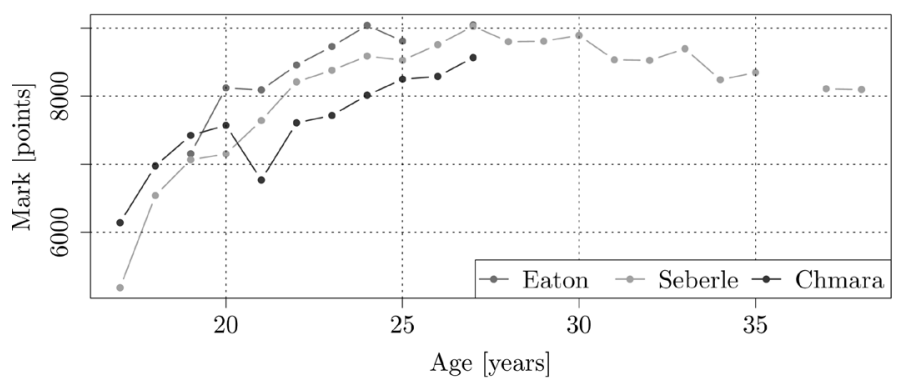

Figure 3. Individual parameters of three selected decathletes in consecutive periods of their sports careers their case, these two periods last 6 and 3 years, respectively (fig. 2e). The individual parameters of the top decathletes in Poland, Europe, and in the world in consecutive periods of their sports careers are shown in figure 3.

\section{Conclusions}

The following conclusions may be drawn based on the findings of the study:

1. Athletes start competing in the decathlon approximately at the age of 17 and attain their personal best scores between the ages of 25 and 30 years. The careers of top decathletes in Poland are much shorter than those of top decathletes in the world.

2. It may take a decathlete 6 (if they are a top Polish athlete) to 10 (if they are a top world athlete) years to attain their highest scores, and while Polish decathletes continue their careers for only 4 years after achieving their best outcome, top world decathletes do so for even up to 13 years.

3. The year when decathletes attain their record score is preceded by a period of the most significant increases in the outcomes achieved, and the period which follows is characterised by the largest decreases in performance.

4. In order to analyse the progression of careers in the men's decathlon in more detail, it is necessary to track changes in the outcomes achieved in each individual event which is part of the decathlon.

\section{Literature}

1. Quarcetani R.L. (2000). Athletics. A history of modern track and field athletics (1860-2000). Mediolan: SEP Editrice.

2. Tidow G. (2000). Challenge decathlon - barriers on the way to becoming the "King of Athletes". New Studies in Athletics 3-4, 39-44.

3. Edouard P., Mori J.B., Samozino B. (2013). Maximal lower extremity power output changes during a decathlon. New Studies in Athletics 3-4, 19-37.

4. Vana Z. (2003). The training of the best decathletes. New Studies in Athletics 4, 15-30.

5. Schrader A. (2011). One event after the other. Leichtathletiktraining 2-3, 46-53. [in German]

6. Maszczyk A. (2013). Analysing and predicting the variability of the outcomes achieved by world athletes in athletics events in the years 1946-2011. Katowice: AWF Katowice. [in Polish]

7. Cieszkowski S., Przednowek K. (2015). The variability of track and field throwing events results achieved by men - Olympic finalists from 1968 to 2012. Scientific Review of Physical Culture 5(3), 209-214.

8. Iskra J., Przednowek K., Walaszczyk A. (2014). Sport career in $400 \mathrm{~m}$ hurdle run in various groups of the best athletes in the world. In $19^{\text {th }}$ Annual Congress of the European College of Sport Science, 2-5 July 2014 (Abstract). Amsterdam: ECSS.

9. Dziadek B., Przednowek K., Cieszkowski S. (2014). A time series analysis of the best results of sprint running in Poland between 2003-2013. Scientific Review of Physical Culture $4(4), 5-10$.

10. Grycmann P., Maszczyk A., Socha T., Gołaś A., Wilk M., Zając T. et al. (2015). Modelling analysis and prediction of 
women javelin throw results in the years 1946-2013. Biology of Sport 32(4), 345-350.

11. Dickwach H., Wagner K. (1997). The age of the best athletes in the world. Leichtathletik 17, 31-32; 19, 31-32. [in German]

12. International Association of Athletics Federations (IAAF). Retrieved January 20, 2016, http://www.iaaf.org/home.

13. Polish Athletics Association. Retrieved February 1, 2016, http://www.pzla.pl/.

14. Matthews P. (2013). Athletics 2013. The International Track and Field Annual. Cheltenham, UK: Sports Book Ltd.

15. van Kuijen H. (1998). 1997 Annual Combined Events. Helmond.

16. Decathlon 2000. Retrieved January 26, 2016, http://www. decathlon2000.com/.

17. Plewnia D. (2016). Tracking the outcomes achieved by athletes in throwing sports. Doctoral dissertation, AWF, Katowice. [in Polish]

18. Biecek P. (2011). R package manual. Wrocław: Oficyna Wydawnicza GiS. [in Polish]

19. Ważny Z. (1970). The physique and age of athletes taking part in the Olympic Games in Rome, Tokyo, and Mexico. Wychowanie Fizyczne i Sport 2, 23-33. [in Polish]
20. Ważny Z., Sozański H. (1980). What determines superior sporting performance? An analysis of selected parameters in the participants of the Olympic Games in Moscow, Montreal, and Munich. Sport Wyczynowy 12, 13-56. [in Polish]

21. Sozański H., Perkowski K., Kosmol A. (1989). Athletics and swimming events at the Olympic Games in Montreal and Seoul. Sport Wyczynowy 1, 21-41. [in Polish]

22. Sozański H., Sadowski J., Czerwiński J. (eds) (2015). Fundamentals of sports training theory and technology. Vol. II. Warszawa-Biała Podlaska: AWF Warszawa, Filia w Białej Podlaskiej. [in Polish]

23. Karvonen M.J. (1955). Age and performance in athletics. Arbeitsphysiologie 16, 110-119.

24. Ważny Z. (1981). Modern training systems for competitive sports. Sport i Turystyka, Warszawa. [in Polish]

25. Butler M. (2012). Olympic Games. Statistics Book. Monaco: IAAF.

26. Butler M. (2015). World Championships. Statistics Book. Monaco: IAAF.

Submitted: March 15, 2016

Accepted: March 29, 2016 